Jurnal Penelitian Perawat Profesional

Volume 3 Nomor 2, Mei 2021

e-ISSN 2715-6885; p-ISSN 2714-9757

http://jurnal.globalhealthsciencegroup.com/index.php/JPPP

\title{
PERAN KELUARGA BERHUBUNGAN DENGAN KEPATUHAN MINUM OBAT KLIEN TUBERKULOSIS
}

\author{
Tatan Lestari*, Lenni Saragih, Feriana Ira Handian \\ Program Studi S1 Keperawatan, STIKes Maharani Malang, Jl. Akordion Timur Selatan No.8b, \\ Mojolangu, Kec. Lowokwaru, Kota Malang, Jawa Timur 65141, Indonesia \\ *tatanlestari_14@gmail.com
}

\begin{abstract}
ABSTRAK
Tuberkulosis Paru merupakan penyakit menular yang saat ini telah menjadi ancaman global, karena hampir sepertiga penduduk dunia telah terinfeksi. Indonesia menempati posisi ketiga dunia untuk banyaknya penderita penyakit tuberculosis. Tingginya angka kematian yang disebabkan oleh tuberculosis paru, salah satu penyebabnya yaitu kurangnya kepatuhan dalam konsumsi obat. Dalam hal ini peran keluarga sangat dibutuhkan untuk mengawasi kepatuhan pasien tuberculosis paru dalam mengkonsumsi obat. Penelitian ini bertujuan untuk mengetahui hubungan peran keluarga dengan kepatuhan minum obat pada klien tuberkulosis di wilayah Puskesmas Kedungkandang Kota Malang. Desain penelitian ini menggunakan desain korelatif, dengan pendekatan cross sectional dengan responden adalah pasien tuberculosis paru di Puskesmas Kedungkandang Kota Malang yang berjumlah 34 orang. Analisis data menggunakan kuesioner yang dibuat langsung oleh peneliti serta telah melalui uji validitas dan reliabilitas. Hasil penelitian dianalisis dengan menggunakan korelasi spearman rank, berdasarkan uji statistik nilai yang didapat $(\mathrm{p}=0,042 ; \alpha=0,05 ; \mathrm{r}=+0,812)$ hasil ini menunjukkan adanya hubungan yang sangat kuat.
\end{abstract}

Kata kunci: kepatuhan klien minum obat; peran keluarga; tuberkulosis

\section{THE ROLE OF THE FAMILY RELATED TO ADHERENCE TO TAKING MEDICATION FOR TUBERCULOSIS CLIENTS}

\begin{abstract}
Pulmonary tuberculosis is an infectious disease that has now become a global threat, because nearly one third of the world's population has been infected. Indonesia occupies the third position in the world for the number of tuberculosis sufferers. The high number of deaths caused by pulmonary tuberculosis, one of the causes is the lack of adherence to drug consumption. In this case, the role of the family is needed to monitor the compliance of pulmonary tuberculosis patients in consuming drugs. This study aims to determine the relationship between the role of the family and adherence to taking medication in tuberculosis clients in the area of Kedungkandang Health Center, Malang City. The design of this study used a correlative design, with a cross sectional approach with 34 respondents who were pulmonary tuberculosis patients at the Kedungkandang Health Center, Malang City. Data analysis used a questionnaire that was made directly by the researcher and has been tested for validity and reliability. The results were analyzed using the Spearman rank correlation, based on the statistical test of the values obtained ( $p=0.042 ; \alpha=0.05 ; r=+0.812)$. These results indicate $a$ very strong relationship. The increasing the role of the family, the increasing the level of compliance with tuberculosis clients at the Kedungkandang Health Center Malang City.
\end{abstract}

Keywords: family roles; client compliance with medication; tuberculosis 


\section{PENDAHULUAN}

Tuberkulosis (TB) paru merupakan penyakit infeksi yang menyerang parenkim paru yang disebabkan oleh Mycobacterium tuberculosis. Penyakit ini dapat juga menyebar ke bagian tubuh lain seperti meningen, ginjal, tulang dan nodus limfe (Somantri, 2017). Sumber penularan pasien TB adalah Basil Tahan Asam (BTA) yang terdapat dalam dahak yang dikeluarkan pada waktu batuk atau bersin. Pasien menyebarkan kuman TBC ke udara dalam bentuk percikan dahak (droplet nuclei/percik renik) (Kemenkes RI, 2014). World Health Organization (WHO) menyatakan bahwa penyakit TB paru saat ini telah menjadi ancaman global, karena hampir sepertiga penduduk dunia telah terinfeksi (Sarwani, D., Nurlela and A, 2012). Tuberkulosis sebagai penyakit menular yang dapat menyerang semua kelompok usia seperti lansia, dewasa maupun anak-anak (Kemenkes RI, 2015).

Penderita TB paru perlu mendapatkan dukungan penuh dari keluarga sehingga mendukung proses kesembuhannya. Peran keluarga bagi penderita TB paru yaitu mengingatkan untuk mengkonsumsi obat tepat waktu, melakukan pemeriksaan rutin dan melakukan perilaku hidup sehat. Peran keluarga secara langsung berpartisipasi mengawasi penderita TB Paru agar meminum obat secara teratur sampai selesai pengobatan, memotivasi agar bersedia untuk periksa ulang dahak sesuai jadwal yang ditentukan dan mewakili penderita mengambil obat (Sulkarnain, 2016). Kepatuhan klien TB paru terhadap pengobatan medis sebagai suatu tindakan pengobatan secara berkelanjutan sehingga mendukung kesembuhannya (Notoatmojo, 2013).
Kepatuhan yang buruk atau terapi yang tidak lengkap adalah faktor yang berperan terhadap lamanya menderita TB paru yang berdampak terhadap kematian (Andareto, 2015). Keberhasilan kepatuhan pengobatan TB tergantung pada peran keluarga pasien dan dukungan dari keluarga, rendahnya peran keluarga dalam memberikan dukungan pengobatan dapat mempengaruhi kepatuhan pasien untuk mengkonsumsi obat (Muttaqin, 2014). Untuk mecapai kesembuhan, penderita juga harus memiliki efikasi diri yang tinggi. Efikasi diri penderita yang rendah akan berakibat pada kegagalan pengobatan. Efikasi diri merupakan keyakinan individu dalam mengelolah perilaku-perilaku tertentu guna memperoleh kesembuhan. Keyakinan diri penderita untuk sembuh dicapai salah satunya dari kognitif atau pengetahuan yang diberikan oleh petugas kesehatan melalui konseling. Penelitian ini bertujuan untuk mengetahui adanya hubungan peran keluarga dengan kepatuhan minum obat pada klien tuberkulosis di wilayah Puskesmas Kedungkandang Kota Malang.

\section{METODE}

Penelitian ini menggunakan desain penelitian Korelatif dengan menggunakan rancangan croos sectional. Sampel dalam penelitian ini 34 responden Sampel dalam penelitian ini 34 responden dari populasi yang termasuk dalam kriteria inklusi dan tidak di pakai apabila termasuk kriteria esklusi. Teknik pengambilan sampel yang digunakan dalam penelitian ini adalah total sampling. Instrument untuk penelitian ini menggunakan kuesioner yang telah di uji validitas dengan hasil rTabel 0,632 dan rhitung0,679-0,810 dan reliabilitasnya dengan nilai yaitu 0,940>0,60. Pengisian kuesioner 
dilakukan oleh masing-masing responden dengan didampingi oleh peneliti ataupun enumerator.

\section{HASIL}

Tabel 1 dijabarkan bahwa penderita TB terbanyak yaitu laki-laki dengan rentang usia 40-60 tahun. Dapat dikatakan bahwa semakin tua usia seseorang maka semakin rentan pula seseorang tersebut terhadap penyakit $\mathrm{Tb}$ ini. Dari data responden, banyak diantara responden yang merupakan pasien dengan lama pengobatan 4-6 bulan dengan kategori pengobatan 6 bulan.

Bagan 1 menunjukkan data, bahwa sebagian besar responden yang memiliki peran keluarga baik ada 26 responden yaitu sebesar $(76,4 \%)$.

Tabel 1.

Karakteristik Responden ( $\mathrm{n}=34)$

\begin{tabular}{lcc}
\hline Karakteristik & $\mathrm{f}$ & $\%$ \\
\hline Jenis Kelamin & 24 & 70.6 \\
Laki-laki & 10 & 29.4 \\
Perempuan & & \\
\hline Usia & 4 & 11,8 \\
18-30 Tahun & 9 & 26,5 \\
31-40 Tahun & 21 & 61,8 \\
41-60 Tahun & & \\
Pendidikan & 3 & 8,82 \\
SD & 7 & 20,59 \\
SMP & 18 & 52,94 \\
SMA & 6 & 17,65 \\
Sarjana & & \\
\hline Lama Pengobatan & 9 & 26,5 \\
$1-3$ bulan & 22 & 64,7 \\
$4-6$ bulan & 3 & 8,8 \\
$>6$ bulan & & \\
\hline Katagori Pengobatan & 31 & 91,2 \\
6 bulan & 3 & 8,8 \\
1 tahun & & \\
\hline
\end{tabular}

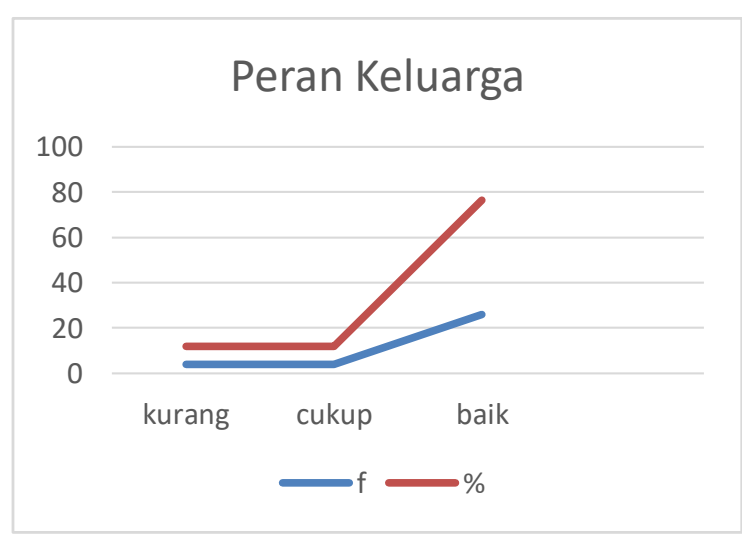

Bagan 1. peran keluarga pasien Tuberkulosis (TBC) 


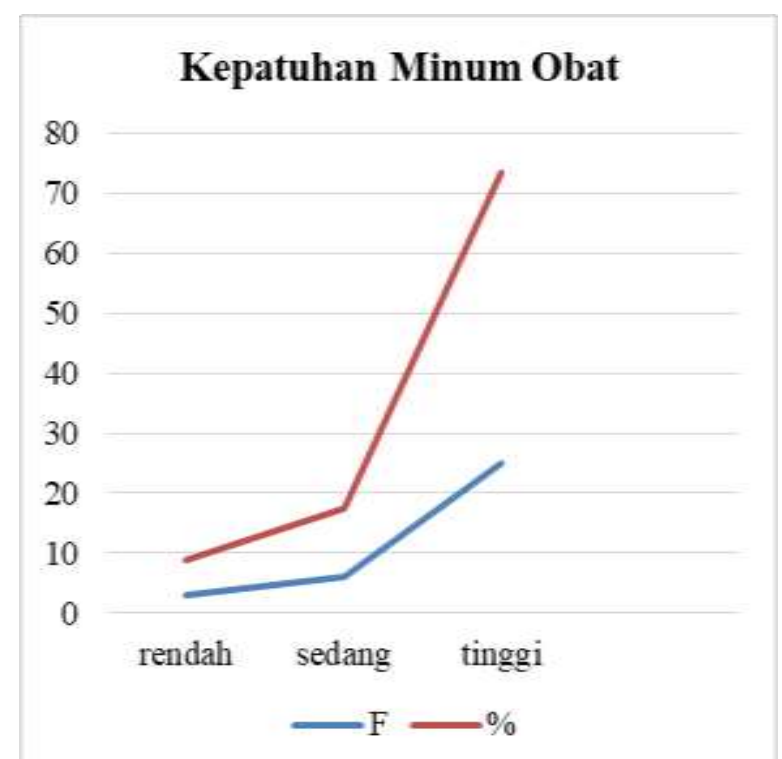

Bagan 2. Kepatuhan Minum Obat Tuberkulosis (TBC)

Tabel 2.

Tabulasi Silang Katagori Pengobatan dengan Lama Pengobatan pada Pasien Tuberkulosis

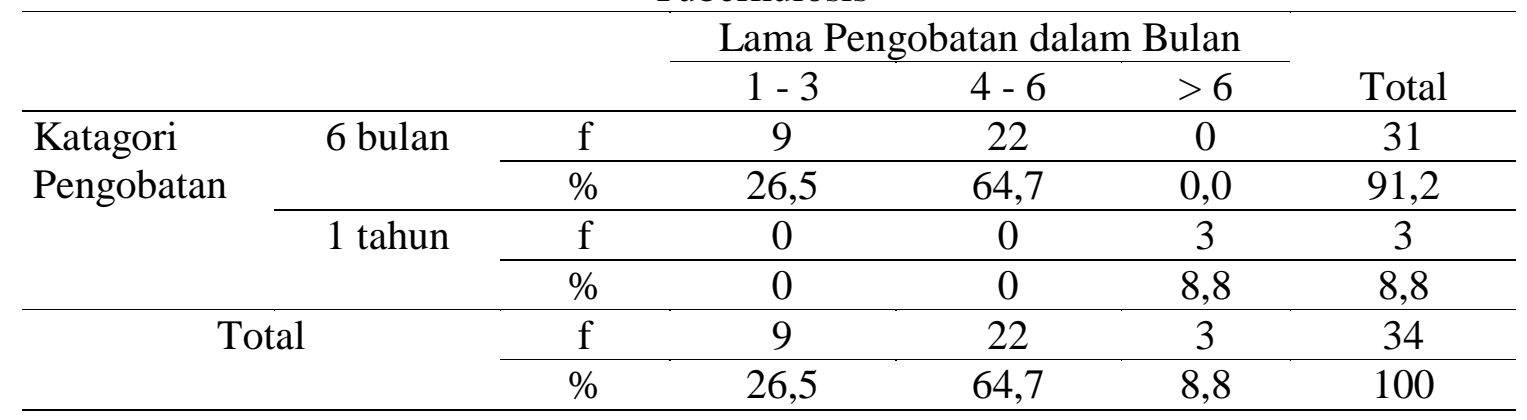

Tabel 3.

Tabulasi Silang Peran Keluarga dengan Kepatuhan Minum Obat pada Pasien Tuberkulosis

\begin{tabular}{|c|c|c|c|c|c|c|}
\hline & & & \multicolumn{3}{|c|}{ Peran Keluarga (X) } & \multirow[b]{2}{*}{ Total } \\
\hline & & & Kurang & Cukup & Baik & \\
\hline \multirow{6}{*}{$\begin{array}{l}\text { Kepatuh- } \\
\text { an minum obat } \\
\text { (y) }\end{array}$} & \multirow[t]{2}{*}{ Rendah } & $\mathrm{N}$ & 2 & 0 & 1 & 3 \\
\hline & & $\%$ & 5,9 & 0 & 2,9 & 8,8 \\
\hline & \multirow[t]{2}{*}{ Sedang } & $\mathrm{N}$ & 2 & 3 & 1 & 6 \\
\hline & & $\%$ & 5,9 & 8,8 & 2,9 & 17,6 \\
\hline & \multirow[t]{2}{*}{ tinggi } & $\mathrm{N}$ & 0 & 1 & 24 & 25 \\
\hline & & $\%$ & 0,0 & 2,9 & 70,6 & 73,5 \\
\hline \multirow[t]{2}{*}{ Total } & & $\mathrm{N}$ & 4 & 4 & 26 & 34 \\
\hline & & $\%$ & 11,8 & 11,8 & 76,5 & 100 \\
\hline
\end{tabular}

Bagan 2 menunjukkan menunjukkan bahwa responden yang patuh dalam menjalani pengobatan Tuberkulosis
(TBC) ada 25 pasien $(73,6 \%)$. Hal ini menunjukan bahwa dari 34 pasien 
sebagian besar responden patuh minum obat Tuberkulosis (TBC).

Tabel 2 dapat diketahui bahwa dari 34 responden yang melakukan pengobatan dalam waktu \pm 6 bulan terdapat 31 orang atau 91,2\% sedangkan jumlah pasien yang melakukan pengobatan \pm 1 tahun terdapat 3 orang atau $8,8 \%$. Tabel 3 dapat diketahui bahwa dari 34 responden memiliki peran keluarga baik dan kepatuhan minum obat pasien Tuberkulosis (TBC) di Puskesmas Kedungkandang Kota Malang baik sebanyak 19 atau 55, 9\%.

Hasil korelasi spearman, diperoleh nilai $p$-value sebesar 0,042 yang artinya $p$ value <a $(0,050)$. Maka Ha diterima yang berarti ada hubungan antara peran keluarga dengan kepatuhan minum obat pada pasien tuberkulosis di Puskesmas Kedungkandang Kota Malang, Sedangkan nilai $\mathrm{r}=+0,812$, membuktikan bahwa terdapat hubungan positif yang kuat antara hubungan peran keluarga dengan kepatuhan minum obat pada klien tuberkulosis. Dimana peran keluarga yang kurang, mampu mengakibatkan pengobatan pada klien tuberkulosis yang kurang optimal. Hasil tabulasi silang didapatkan 19 (55,9\%) peran keluarga yang baik menghasilkan sebanyak 26 (76,5\%) dalam melakukan kepatuhan minum obat pada klien tuberculosis.

\section{PEMBAHASAN}

\section{Peran Keluarga dalam Kepatuhan Minum Obat pada Pasien Tuberkulosis (TBC)}

Hasil studi ini menunjukkan peran keluarga yang baik dapat meningkatkan kepatuhan meminum obat. Kerjasama keluarga dalam memantau kepatuhan meminum obat berdampak signifikan dalam kepatuhan responden untuk meminum obat, terlebih konsumsi obat
TB membutuhkan waktu yang lama yaitu 6 bulan tanpa putus. Selain itu pengetahuan keluarga tentang TB juga diperlukan untuk menambah wawasan dalam pengawasan minum obat baik dengan penyuluhan ataupun dengan pelatihan. Dalam penelitian yang dilakukan oleh (Jufrizal, Hermansyah, 2016) menyatakan ada hubungan peran keluarga sebagai PMO dengan tingkat keberhasilan pengobatan pada penderita TB Paru $(\mathrm{p}=0,000 ; \quad \mathrm{OR}=20,476)$. Diperlukan pelatihan seputar TB untuk keluarga pendamping atau pengawas minum obat untuk menambah wawasan, guna mengoptimalkan peran pengwasan dalam kepatuhan meminum obat oleh penderita TB. Keluarga sebagai orang terdekat barang tentu lebih baik dalam peran pengawasan dibandingkan Kader ataupus petugas kesehatan.

\section{Kepatuhan Minum Obat Tuberkulosis (TBC)}

Kepatuhan dalam meminum obat TB meningkatkan kesembuhan dari responden yang menderita TB. Semakin baik kepatuhan dalam meminum obat maka semakin tinggi angka kesembuhannya. Hal ini selaras dengan penelitian yang telah dilakukan oleh Yuda and Utoyo (2018) yang menyatakan bahwa keteraturan minum obat sangat berpengaruh terhadap kesembuhan pasien dengan TB yaitu sekitar 93,75\%. Jika hal ini terus diterapkan baik kepada pasian TB di Malang ataupun secara global, maka angka kejadian TB akan dapat ditekan atau menurun. Hal itu juga dapat berarti angka mortalitas karena TB dapat menurun. Kepatuhan penderita dalam meminum obat ini dapat juga diperngaruhi oleh kemauan untuk sembuh. Jika penderita berkemauan tinggi untuk sembuh maka kedisiplinan dalam mengkonsumsi obat juga akan diterapkan. 


\section{Hubungan antara Peran Keluarga dengan Kepatuhan Minum Obat pada Pasien Tuberkulosis}

Hasil studi ini menunjukkan bahwa ada hubungan antara peran keluarga dengan kepatuhan minum obat Tuberkulosis (TBC) di Puskesmas Kedungkandang Kota Malang. Peran keluarga yang baik disebabkan karena adanya kesadaran yang tinggi dari keluarga untuk saling memelihara dan memberi perawatan kesehatan pada anggota keluarga yang sakit sehingga dapat mempengaruhi keberhasilan perawatan pada penderita Tuberkulosis paru. Hal ini sesuai dengan penelitian yang dilakukan oleh Andri Saputra Yoisangadji, Franckie, dan Maramis (2016) yang menyatakan hubungan anatara PMO dengan kepatuhan minum obat TB pada pasien TB di wilayah kerja Puskesmas Sario. Namun peran keluarga yang baik tidak akan menghasilkan kepatuhan penderita TB untuk minum obat jika penderita TB itu sendiri tidak memiliki keinginan yang kuat utuk sembuh. Baik peran keluarga, kepatuhan meminum obat oleh penderita TB dan keinginan penderita TB untuk sembuh harus memiliki hubungan yang kuat yang diharapkan akan menjadi pondasi dalam tercapainya penurunan angka kejadian TB baik di Malang ataupun secara menyeluruh.

\section{SIMPULAN}

Berdasarkan penelitian hubungan yang kuat antara peran keluarga dengan kepatuhan minum obat pada klien Tuberkulosis (TBC) di Puskesmas Kedungkandang Kota Malang. Dari pembahasan yang dijabarkan dapat ditarik kesimpulan bahwa sebagian besar responden memiliki peran keluarga baik, sebagian besar responden patuhan minum obat Tuberkulosis (TBC) baik. Peneliti menyimpulkan terdapat hubungan yang kuat antara peran keluarga dengan kepatuhan minum obat pada klien Tuberkulosis (TBC) di Puskesmas Kedungkandang Kota Malang.

\section{DAFTAR PUSTAKA}

Andareto, O. (2015) Penyakit Menular Sekitar Anda. Jakarta: Serambi Distribusi.

Andri Saputra Yoisangadji, Franckie R.R Maramis, A. A. R. (2016) 'Hubungan Antara Pengawas Penelan Obat (PMO) dan Peran Keluarga dengan Kepatuhan Minum Obat Pada Pasien Tuberkulosis di Wilayah Kerja Puskesmas Sario Kota Manado', PHARMACONJurnal Ilmiah Farmasi - UNSRAT, Vol. 5, p. No. 2 MEI 2016 ISSN 2302-2493. Available at: https://ejournal.unsrat.ac.id/index. php/pharmacon/article/view/1218 1/11761.

Jufrizal, Hermansyah, M. (2016) 'Peran Keluarga Sebagai Pengawas Minum Obat (Pmo) Dengan Tingkat Keberhasilan Pengobatan Penderita Tuberkulosis Paru', Jurnal Ilmu Keperawatan, 4(1), pp. 25-36.

Kemenkes RI (2014) 'pedoman nasional pengendalian tuberkulosis', Direktorat Jendral Pengendalian Penyakit dan Penyehatan Lingkungan.

\section{Kemenkes RI (2015) 'Sekretariat Jendral Profil Kesehatan Indonesia 2014', Kementrian Kesehatan Republik Indonesia.}

\footnotetext{
Muttaqin, A. (2014) Buku Ajar Asuhan Keperawatan Klien Dengan Gangguan Sistem Pernapasan. Jakarta: Salemba Medika.
} 
Notoatmojo, S. (2013) Kesehatan Masyarakat Ilmu dan Seni. Jakarta: PT Asdi Mathasatya.

Sarwani, D., Nurlela, S. and A, Z. (2012) 'Faktor Resiko Multidrug Resistent Tuberkulosis (MDRTB)', Jurnal kesehatan Masyarakat, 08(01). Available at: http://unnes.ac.id/nju/index.php/k emas.

Somantri, I. (2017) Asuhan Keperawatan Pada Pasien Dengan Gangguan Sistem Penapasan. jakarta: salemba medika.

Sulkarnain, N. (2016) Asuhan keperawatan TB Paru. Jakarta: Salemba Medika.

Yuda, H. T. and Utoyo, B. (2018) 'Peran Pengawas Menelan Obat (PMO) terhadap Hasil Pengobatan Penderita Tuberculosis Paru Di Wilayah Puskesmas Gombong II 1Hendri', Jurnal Ilmiah Kesehatan, XI(II), pp. 393-398. 
Jurnal Penelitian Perawat Profesional, Volume 3 No 2 Hal 429 - 436, Mei 2021 Global Health Science Group 